\title{
Functional Approach to Development of Hybrid Technology of Cutting Diamond Carbides
}

\author{
Salenko A.F. ${ }^{1}$, Shchetinin V.T. ${ }^{1}$, Gabuzian G.V. ${ }^{1}$, Nikitin V.A. ${ }^{1}$, Klymenko S.A. ${ }^{2}$, Potapov A.M. ${ }^{3}$, Tanovic Lj. ${ }^{4}$ \\ ${ }^{1}$ Kremenchuk Mykhailo Ostrohradskyi National University \\ ${ }^{2}$ V.N. Bakul Institute of Superhard Materials of the National Academy of Sciences of Ukraine \\ ${ }^{3}$ Public Enterprise "Design Bureau "Yuzhnoie" \\ ${ }^{4}$ University of Belgrade
}

Abstract: Background: Modern composite materials have a number of advantages in comparison with the traditionally used ones and allow implementing new methods of processing, which makes the finished product cheaper and makes its use more efficient.

Objective: In order to improving the surface quality and productivity taken by A functional approach

Method: A functional approach to the development of cutting technologies for Carbide and Super Hard Multilayered Composites is considered. It allows, by alternating the effects of different nature, to obtain qualitative edges, to lower the residual stresses in the surface layers, and to achieve a high surface quality. The essence of the approach is that the method of impact is determined on the basis of a morphological search of options for the execution of individual surface elements, each of which, combined into a set, uniquely forms the function of the finished product. The cutting is determined by a rational sequence of execution of technological transitions, provided that each harmful intermediate function at the finish stage turns into neutral or complements the required useful function.

Results: Examples of figured cutting of plates from polycrystalline diamond-containing materials are given, the results of obtaining qualitative edges are shown.

Conclusion: Thanks to the proposed technology based on the use of a functionally oriented approach, the functions of the tool for cutting are divided between the tool itself and the product part. As a result, the processing speed increases more than 3 times, and a high cut quality is achieved.

Keywords: Hybrid technology; super hard composites; hydro jet; hydro abrasive cutting; laser cutting; water jet guided laser treatment

\section{Introduction}

Dimensional processing of products made from hard alloys and superhard materials, in particular, contour cutting prismatic and circular plates, arbitrary shaped flat workpieces is of a certain interest for contemporary high-technology production, as it enables creation of half-finished or final products of various geometric shapes from workpieces obtained by sintering.

In this case conventional methods, first of all abrasive processing, electroerosion cutting, find limited application, which is caused by special features of the structural condition and physical and mechanical properties of the materials of the processed workpieces. Processing of products made from laminated compounds is especially complicated as there is a danger of breakage of adhesion bonds in the "base-surface layer" plane. Workpieces made from such products include diamond-carbides composite (DC) containing an upper (working) layer of polycrystal superhard composite

\footnotetext{
Copyright (C) 2018 Salenko A.F et al.

doi: $10.18063 / \mathrm{msmr} . v 2 \mathrm{i} 1.460$

This is an open-access article distributed under the terms of the Creative Commons Attribution Unported License

(http://creativecommons.org/licenses/by-nc/4.0/), which permits unrestricted use, distribution, and reproduction in any medium, provided the original
} work is properly cited. 
on the basis of synthetic diamond (PCD) and a lower (supporting) layer from hard alloy based on tungsten carbide $(\mathrm{HA})^{[1]}$, obtained by sintering in high-pressure apparatus.

It was demonstrated that blasting, first of all liquid blasting ${ }^{[2]}$, as well as laser blasting, have good prospects in industrial use for cutting flat workpieces from polycrystal superhard materials (PSHM) and HA, as they allow creation of the cut surface with sufficient efficiency. However, the problems of provision of high quality of the worked surfaces of the products have not yet been solved in full.

So, surfaces of products from HA and PSHM obtained by the mentioned methods are characterized by high roughness and essential deviation of the shape. In paper ${ }^{[3]}$ it is shown that hybrid processing methods based on combination of different ways of power and other flows impact on the material make it possible to essentially reduce working hours necessary for production, improve the quality of processing. At the same time, analysis of the final product from the point of view of its useful functions ${ }^{[4,5]}$ enables improvement of the method and scientific substantiation of most rational ways of impact on the workpiece to achieve the maximum quality level.

The solution to these problems can be found in the use of an innovative approach to development of hybrid working methods, proposed by the authors; its essence consists in provision of useful functions of the product on the basis of morphological analysis of variants of combination of power or energy flows generating a hybrid production process.

The purpose of the paper consists in development of principles of functional approach to creation of hybrid processes as a morphological combination of various ways of power or energy flows impact on the worked piece when functions and properties of the final product are formed by totality of results of some technological transitions realized on micro-, meso- or macro-levels of the product.

\section{Approaches to problem solution and research methods}

Functional approach to development and creation of new machines, objects and complex technical systems was studied by many researchers, in particular, E.I. Galibardov ${ }^{[6]}$. He states that any material object is characterized by a certain totality (matrix) of functions among which it is possible to single out useful, harmful and neutral functions (Fig. 1). Unlike a material approach, a functional approach is based on the fact that the product is made to perform a number of functions provided by corresponding material carriers (the cheapest ones or the ones with the least costly manufacturing steps).

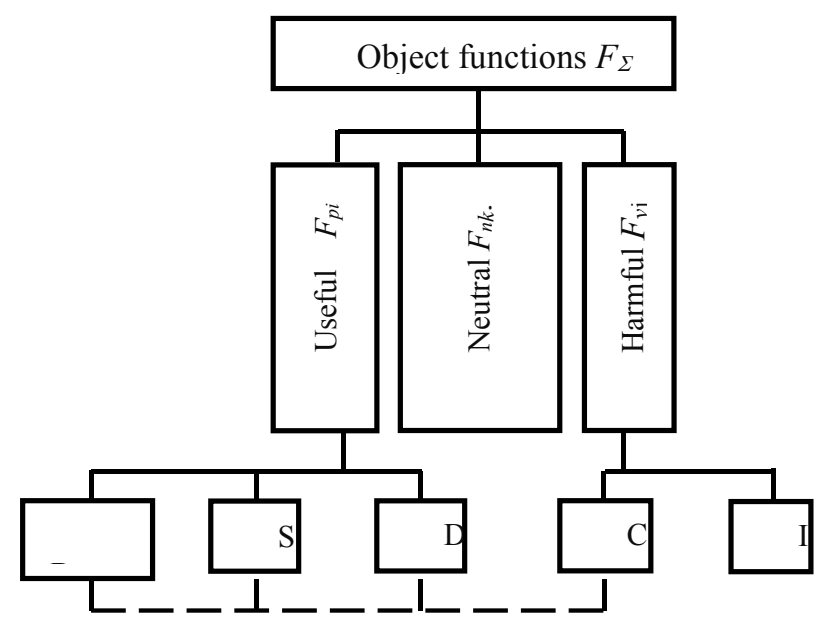

Figure 1; Classification of the object functions: B - basic; S - secondary; D - derived (obtained without special provision); C connected (accompany useful functions); I - independent.

This approach can also be applied to working technologies: the manufacturing process expressed through material carriers is to be minimized according to criteria taken into consideration - working time, cost price, quality. Systemized data of this approach are presented in a number of papers, e.g. ${ }^{[7-9]}$.

The idea of modularity of technological processes (TP) and their functional orientation can develop in the 
following direction.

As all types of functions (useful, neutral and harmful) are available in a final product, manufacturing steps are to be oriented in such a way that harmful functions be weakened and useful ones, in their turn, be obtained in the minimum number of steps. Under these conditions a technological process can be considered prospective if weakening or complete elimination of harmful functions takes place along with creation of useful functions during the steps.

Analysis of typical products of mechanical engineering from the point of view of functional approach reveals that practically always creation of a particular useful consumer function $F_{p}$ will go together with manifestation of neutral $F_{n}$ and harmful $F_{v}$ functions. Then a product having only useful (under certain conditions) functions is ideal from the point of view of operation:

$\mathrm{F}_{\mathrm{p}}=\mathrm{F}_{\mathrm{pz}}, \mathrm{F}_{\mathrm{v}}=0, \mathrm{~F}_{\mathrm{n}} \rightarrow \min$,

where $\mathrm{F}_{\mathrm{pz}}$ - product useful functions having the following matrix of consumer properties:

$\mathrm{P}=\sum_{\mathrm{i}=1}^{\mathrm{l}} \mathrm{F}_{\mathrm{pi}}+\sum_{\mathrm{i}=1}^{\mathrm{m}} \mathrm{F}_{\mathrm{nj}}+\sum_{\mathrm{k}=1}^{\mathrm{p}} \mathrm{F}_{\mathrm{vk}}$.

Hence, an equation of restrictions (1) and optimization (2) makes it possible to choose the most rational material carriers of functions on the basis of morphological analysis, then to pass to material carriers in the technological process creating these functions.

As there is a functional interrelation between separate functions, i.e.

$\mathrm{F}_{\mathrm{v}}=\mathrm{pF}_{\mathrm{p}}, \mathrm{F}_{\mathrm{n}}=\mathrm{qF}_{\mathrm{p}}$.

taking into account the fact that a function is created by a separate TP step in the form of transformation element

$\mathrm{W}_{\mathrm{p}}$ (2) can be presented in the following form:

$\mathrm{P}=\sum_{\mathrm{i}=1}^{\mathrm{l}} \mathrm{W}_{\mathrm{p}} \mathrm{F}_{\mathrm{pi}}+\sum_{\mathrm{i}=1}^{\mathrm{m}} \mathrm{W}_{\mathrm{n}} \mathrm{qF} \mathrm{F}_{\mathrm{pj}}+\sum_{\mathrm{k}=1}^{\mathrm{p}} \mathrm{W}_{\mathrm{v}} \mathrm{pF}_{\mathrm{pk}}$.

Taking into consideration the fact that TP cannot be aimed at creation of harmful functions and properties in the product, minimization of the unnecessary functions is expressed by dependence:

$\mathrm{P}=\sum_{\mathrm{i}=1}^{\mathrm{l}} \mathrm{W}_{\mathrm{p}} \mathrm{F}_{\mathrm{pi}}+\sum_{\mathrm{i}=1}^{\mathrm{m}} \overline{\mathrm{W}_{\mathrm{p}}} \mathrm{qF} \mathrm{pj}+\sum_{\mathrm{k}=1}^{\mathrm{p}} \overline{\mathrm{W}_{\mathrm{p}}} \mathrm{pF}_{\mathrm{pk}}$,

or, after transformation, in the following way:

$\mathrm{P}=\sum_{\mathrm{i}=1}^{\mathrm{l}} \mathrm{F}_{\mathrm{pi}}\left(\mathrm{W}_{\mathrm{p}}+\overline{\mathrm{W}_{\mathrm{p}}} \mathrm{q}+\overline{\mathrm{W}_{\mathrm{p}}} \mathrm{p}\right)$.

Approaching of the totality of the product properties to the ideal implies transformation of summands $\overline{W_{n}} q$ and $\overline{\mathrm{W}_{\mathrm{v}}} \mathrm{p}$ into zero, which is possible under the condition of absence of functional relation between useful and harmful properties of the product or under the conditions that the process of obtaining useful properties due to a particular TP step is at the same time the inverse one as to the occurring harmful functions. Availability and interrelation of TP separate elements enable presentation of (6) in the following way:

$$
\mathrm{P}=\sum_{\mathrm{i}=1}^{\mathrm{l}} \mathrm{F}_{\mathrm{pi}}\left(\mathrm{W}_{\mathrm{p}}+\overline{\mathrm{W}_{\mathrm{p}}} \mathrm{q}+\overline{\mathrm{W}_{\mathrm{p}}} \mathrm{p}+\overline{\mathrm{W}}_{\mathrm{p}}(\mathrm{p}+\mathrm{q})\right) .
$$

For totality of alternative variants of TP the obtained equality is supplemented by quantitative signs of every function the integral sum of which is equal to 1 , then

$$
\mathrm{I}=\sum_{\mathrm{i}=1}^{\mathrm{l}} \mathrm{F}_{\mathrm{pi}}\left(\mathrm{b}_{\mathrm{ki}} \mathrm{W}_{\mathrm{pi}}-\mathrm{b}_{\mathrm{vi}} \overline{\mathrm{W}_{\mathrm{pi}}} \mathrm{p}-\mathrm{b}_{\mathrm{ri}} \overline{\mathrm{W}}_{\mathrm{pi}}(\mathrm{p}+\mathrm{q})\right) \text {. (8) }
$$

under the condition that $\overline{b_{n i} W_{\mathrm{pi}}} q=0$. Here $b_{k i}, b_{v i}-$ corresponding weight coefficients of each of the useful, harmful functions; $b_{\mathrm{ri}}$ - weight coefficients of interaction of independent steps revealing reserves in improvement of output properties of the final product.

Describing the object by setting its initial condition $\mathrm{C}_{\mathrm{n}}$, as a totality of parameters characterizing the form and dimensions of the workpiece, its physical and mechanical properties and final condition $C_{k}$ via particular forms (dimensions, relative position of the surfaces, physical and mechanical properties, etc.), the technological transformation function $\varphi_{0}$ is presented as:

$$
\varphi_{0}:\left\{\begin{array}{c}
\mathrm{C}_{\mathrm{n} 2} \\
:
\end{array}\right\} \rightarrow\left\{\begin{array}{c}
\mathrm{C}_{\mathrm{k} 2} \\
:
\end{array}\right\}
$$

where $\mathrm{C}_{\mathrm{nR}}-r$-th elementary property of the workpiece; $\mathrm{C}_{\mathrm{kT}}-t_{\text {-th }}$ elementary property of the product; $\mathrm{R}, \mathrm{T}-$ total number of parameters of the workpiece and the product, respectively. The function $\varphi_{0}=\Sigma \mathrm{W}_{\mathrm{i}} \mathrm{E}_{\mathrm{j}}, \mathrm{E}_{\mathrm{j}}-$ the product separate elements creating its properties.

As the product separate functions expressed via obtaining parameters of geometric accuracy, condition, structure, 
etc. can be generated in different ways, it is expedient to create morphological tables that may provide the basis for search of more rational variants of combination of technological actions.

Let the created product realize some totality of functions $\mathrm{F}_{1} \ldots \mathrm{F}_{1}$. To guarantee them the elements of condition of workpiece $\mathrm{E}_{\mathrm{ki}}$ are to be formed in such a way (Fig. 2), that

$\mathrm{F}_{1}=\mathrm{C}_{\mathrm{ki}}=\mathrm{C}_{\mathrm{pi}} \mathrm{W}_{\mathrm{pj}}=\Sigma \mathrm{E}_{\mathrm{ki}} \mathrm{W}_{\mathrm{pj}}$.

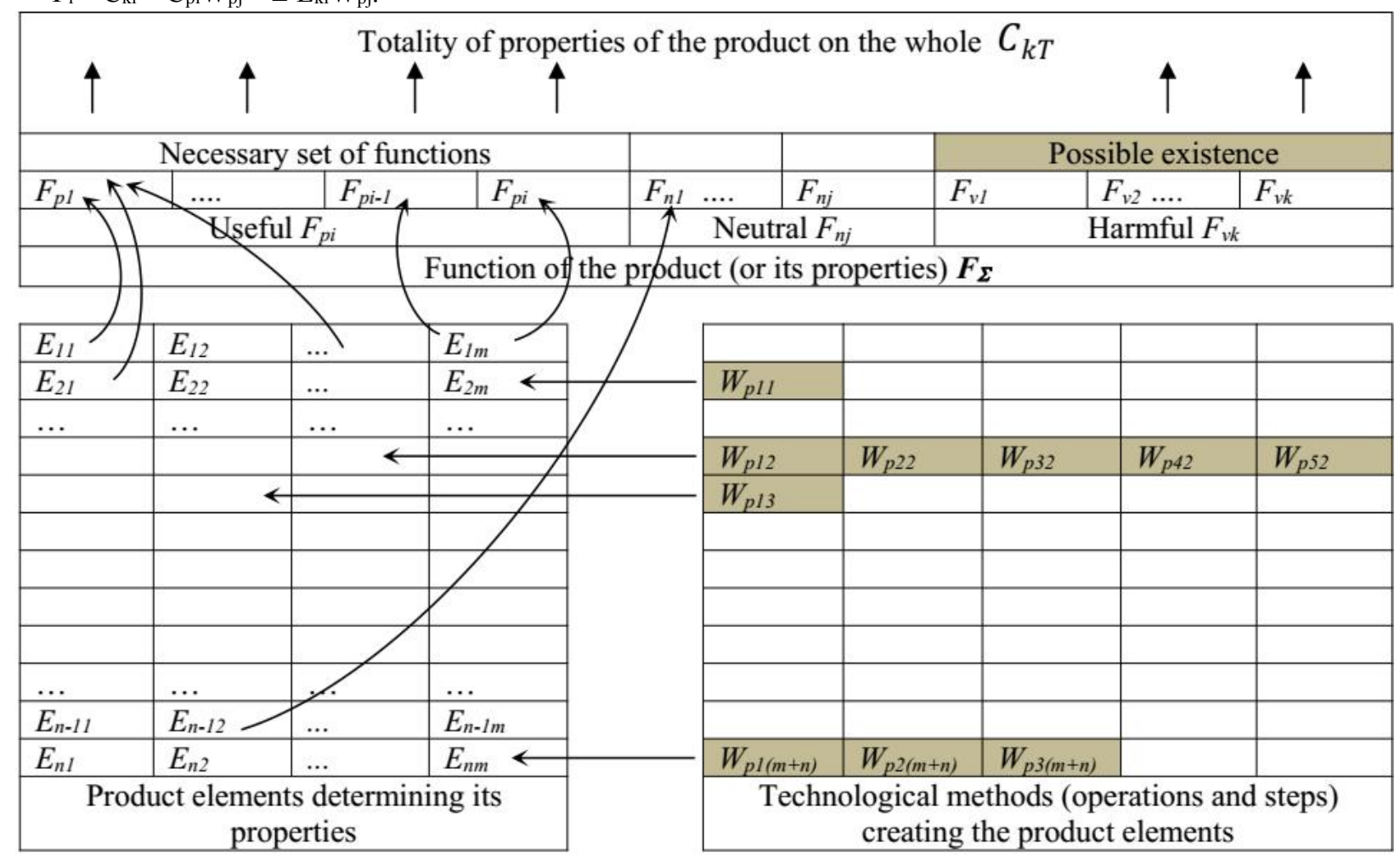

Figure 2; Provision of the product functions $\mathrm{F}_{\mathrm{pi}}$ by separate elements when they are generated by TP steps $\mathrm{W}_{\mathrm{ij} \text {. }}$

Application of this approach makes it possible to reveal rational sequence of TP steps, find causes of occurrence of harmful functions and eliminate them (or invert), and also to determine the possibility for hybridization of the process to meet condition (1).

As generation of assigned functions is a multivariant task (Fig.2, table1), logical relations obtained on the basis of morphological analysis can be simplified according to the known rules of Boolean algebra provided that restrictions be met according equation (7). In this case differentiation or hybridization of operation may have new effects that are to be taken into account by corresponding weight coefficients that shows in equation (8).

\begin{tabular}{|l|l|l|l|l|}
\hline No. $\mathbf{n} / \mathbf{I}$ & Product functions & Elements provision & $\begin{array}{l}\text { Material carriers - TP } \\
\text { steps }\end{array}$ & $\begin{array}{l}\text { Probable } \\
\text { harmful functions }\end{array}$ \\
\hline 1 & 2 & 3 & 4 & 5 \\
\hline 1 & $\mathrm{~F}_{\mathrm{p} 1}$ & $\mathrm{E}_{2} \cap \mathrm{E}_{3} \cap \mathrm{E}_{4}$ & $\mathrm{~W}_{\mathrm{p} 1} * \mathrm{~W}_{\mathrm{pj}}+\mathrm{W}_{\mathrm{p} 3}$ & $-\cdots-$ \\
\hline 2 & $\mathrm{~F}_{\mathrm{p} 2}$ & $\mathrm{E}_{2} \cap \mathrm{E}_{3}+\mathrm{E}_{7} \cap \mathrm{E}_{8}$ & $\begin{array}{l}\mathrm{W}_{\mathrm{p} 4} * \mathrm{~W}_{\mathrm{p} 7}+\mathrm{W}_{\mathrm{p} 3} \\
* \mathrm{~W}_{\mathrm{p} 5}+\mathrm{W}_{\mathrm{p} 2}\end{array}$ & $\mathrm{~F}_{\mathrm{v} 1}$ \\
\hline$\ldots$ & & & & \\
\hline $\mathrm{L}$ & $\mathrm{F}_{\mathrm{p} 1}$ & & & \\
\hline
\end{tabular}

Table 1. Components of the product useful functions and their provision by TP

The product properties are generated as a result of a number of manufacturing steps during which a complete or partial change of the initial properties takes place. Technological transformation of a workpiece into a product is achieved by purposeful total technological impacts $\mathrm{W}_{\mathrm{ij}}\left(\mathrm{t}_{\mathrm{k}}\right)$ of material $\mathrm{S}_{\mathrm{o}}\left(\mathrm{t}_{\mathrm{k}}\right)$, energy $\mathrm{E}_{\mathrm{o}}\left(\mathrm{t}_{\mathrm{k}}\right)$ and information $\mathrm{I}_{0}\left(\mathrm{t}_{\mathrm{k}}\right)$ types 
which enables presentation of a scheme of output properties generation according to Fig. 3 and writing down:

$\mathrm{W}_{\mathrm{ij}}\left(\mathrm{t}_{\mathrm{k}}\right)=\mathrm{S}_{\mathrm{o}}\left(\mathrm{t}_{\mathrm{k}}\right) \cup \mathrm{E}_{0}\left(\mathrm{t}_{\mathrm{k}}\right) \cup \mathrm{I}_{\mathrm{o}}\left(\mathrm{t}_{\mathrm{k}}\right)$.

Then, on the grounds of the condition that tool technological impacts on the product are to be performed at the levels from nano-areas to the product on the whole, and the product is a $3 \mathrm{D}$ object, to realize the totality of variants of technological impacts the morphological matrix will correspond to the following form:

$$
A_{3}^{\Pi}=\left\|\begin{array}{|ccccccccccccc}
\Pi_{11}^{S} & \Pi_{12}^{S} \ldots & \Pi_{21}^{S} & \Pi_{22}^{S} \ldots & H_{11}^{S} & H_{12}^{S} \ldots & H_{21}^{S} & H_{22}^{s} \ldots & E_{11}^{S} & E_{12}^{S} \ldots & E_{21}^{S} & E_{22}^{S} \ldots \\
\Pi_{11}^{t} & \Pi_{12}^{t} \ldots & \Pi_{21}^{t} & \Pi_{22}^{t} \ldots & H_{11}^{t} & H_{12}^{t} \ldots & H_{21}^{t} & H_{22}^{t} \ldots & E_{11}^{t} & E_{12}^{t} \ldots & E_{21}^{t} & E_{22}^{t} \ldots \\
\Pi_{11}^{v} & \Pi_{12}^{v} \ldots & \Pi_{21}^{v} & \Pi_{22}^{v} & H_{11}^{v} & H_{12}^{v} \ldots & H_{21}^{v} & H_{22}^{v} \ldots & E_{11}^{v} & E_{12}^{v} \ldots & E_{21}^{v} & E_{21}^{v} \ldots
\end{array}\right\|
$$

where $\Pi_{11}^{s}, \Pi_{12}^{s}, \ldots ; \Pi_{21}^{s}, \Pi_{22}^{s}, \ldots ; \Pi_{11}^{t}, \Pi_{12}^{t}, \ldots ; \Pi_{21}^{t}, \Pi_{22}^{t}, \ldots ; \ldots \Pi_{11}^{v}, \Pi_{12}^{v}, \ldots ; \Pi_{21}^{v}, \Pi_{22}^{v}, \ldots ; \ldots$ - variants of discontinuous technological actions along the corresponding axes $\mathrm{s}, \mathrm{t}$ and $\mathrm{v}$ of the coordinate system of $\mathrm{s}, \mathrm{t}, \mathrm{v} ; \mathrm{H}_{11}^{s}$, $\mathrm{H}_{12}^{s}, \ldots ; \mathrm{H}_{21}^{s}, \mathrm{H}_{22}^{s}, \ldots ; \mathrm{H}_{11}^{t}, \mathrm{H}_{12}^{t}, \ldots ; \mathrm{H}_{21}^{t}, \mathrm{H}_{22}^{t}, \ldots ; \mathrm{H}_{11}^{v}, \mathrm{H}_{12}^{v}, \ldots ; \mathrm{H}_{21}^{v}, \mathrm{H}_{22}^{v}, \ldots$ - different variants of continuous technological actions along the axes $\mathrm{s}, \mathrm{t}$ and $\mathrm{v}$ of the coordinate system of $\mathrm{s}, \mathrm{t}, \mathrm{v} ; \mathrm{E}_{11}^{s}, \mathrm{E}_{12}^{s}, \ldots ; \mathrm{E}_{21}^{s}, \mathrm{E}_{22}^{s}, \ldots ;-$ different variants of one-time technological actions.

Presence of variants of discontinuous technological actions makes it possible to consider processing of one element of the product in the form of a successive totality of different actions. In this case if the element geometric characteristics (e.g. flatness, accuracy of linear dimensions) are its output index, this process can be realized by different types of actions that more completely correspond to the properties of the workpiece elements. As actions providing the conditions for minimum error of the shape are to be taken without reinstallation of the workpiece and change of its position in the fixation and orientation device, such processes should be considered hybrid ones.

Let some element $\mathrm{E}_{\mathrm{m}}$ of a product is obtained due to realization of discontinuous technological actions $\Pi_{i i}^{t}$ and $\Pi_{i i+k}^{t}$. It can be expected that $\mathrm{k}$ tools, accordingly, will be required for the realization. However, if it is taken into account that a new tool is created on the basis of the known ones, i.e expression $R_{n j}=\bigcap_{i=1}^{\rho_{i}} R_{s i}$ takes place, where $\mathrm{R}_{\mathrm{nj}}$ - field of creation of new types of tools; $R_{s i}-i$-th totality of the known engineering solutions; $\rho_{i}$ - weight of the subset of the known engineering solutions, then the newly created tool can combine means for fundamentally different types of actions (Fig. 3).

Let totalities of properties of two tools represent expressions

$$
\begin{aligned}
& \begin{array}{c}
I_{1}=\left\{\begin{array}{ccc}
\rho_{11} S^{1}{ }_{11} & \rho_{21} S^{1}{ }_{21} & \rho_{k 1} S^{1}{ }_{k 1} \\
\ldots & \ldots & \ldots \\
\rho_{1 j} S_{1 j}^{1} & \rho_{2 j} S^{1}{ }_{2 j} & \rho_{k j} S^{1}{ }_{k j}
\end{array}\right\} \quad I_{2}=\left\{\begin{array}{ccc}
\rho_{11} S^{2}{ }_{11} & \rho_{21} S^{2}{ }_{21} & \rho_{k 1} S^{2}{ }_{k 1} \\
\ldots & \ldots & \ldots \\
\rho_{1 j} S^{2}{ }_{1 j} & \rho_{2 j} S^{2}{ }_{2 j} & \rho_{k j} S_{k j}{ }_{k j}
\end{array}\right\} . \quad\left\{\begin{array}{l}
C_{k 1} \\
C_{k 2} \\
\ldots \\
C_{k T}
\end{array}\right\} \\
I_{1} \subset \mathrm{H}_{11}^{s}, \mathrm{H}_{12}^{s}, \ldots \mathrm{H}_{11}^{t},
\end{array} \\
& \mathrm{H}_{12}^{t}, \ldots ; \mathrm{H}_{11}^{v}, \mathrm{H}_{12}^{v}, \ldots ; \ldots . . \quad \begin{array}{l}
2, \ldots \mathrm{H}_{21}, \mathrm{H}_{22}, \ldots \mathrm{H}_{21}, \\
\mathrm{H}_{22}^{t}, \ldots ; \mathrm{H}_{21}^{v}, \mathrm{H}_{22}^{v}, \ldots ; \ldots
\end{array}
\end{aligned}
$$

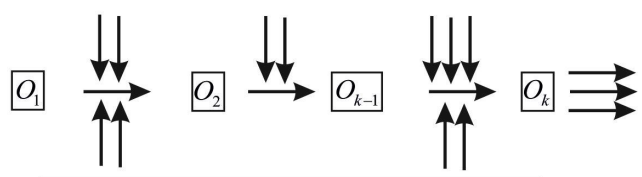

$$
\begin{aligned}
& \underbrace{\begin{array}{l}
I_{g} \subset \Pi_{11}^{s}, \Pi_{12}^{s}, \ldots ; \Pi_{21}^{s}, \Pi_{22}^{s}, \ldots ; \\
\Pi_{11}^{t}, \Pi_{12}^{t}, \ldots ; \Pi_{21}^{t}, \Pi_{22}^{t}, \ldots ; \Pi_{11}^{v}, \Pi_{12}^{v}, \ldots ; \Pi_{21}^{v}, \Pi_{22}^{v}, \ldots
\end{array}} \\
& N\left(t_{k}\right)=S_{0}\left(t_{k}\right) U E_{0}\left(t_{k}\right) U I_{0}\left(t_{k}\right)
\end{aligned}
$$

Figure 3; Generation of the product properties during manufacturing steps by conventional (upper) and hybrid (lower) tools.

Then a hybrid tool obtained on the basis of the principle of morphological search and combination of properties will consist of $\mathrm{m}$ elements (lower). Because $\mathrm{k}$ and $\mathrm{j}$ is a elements of different initial tools (upper), we can assert that $\mathrm{m}$ 
$<\mathrm{k}+\mathrm{j}$, as some of properties of initial tools can be combined. Thus, the index of hybridization of the created instrument $k_{g}=\frac{k+j}{m}$.

is - $m$. This index provides the possibility to find rational engineering solutions for a hybrid tool on the grounds of a totality of the required properties of the worked product and also the possibilities to achieve them by available means.

Consider specific features of application of this approach to creation of hybrid processes for working of diamond-bearing products intended to be used as tools. Such products are rather simple, the number of elements $\mathrm{E}_{\mathrm{i}}$, defining functions $F_{j}$ of the latter is not large and, as a rule represents several surfaces making working surfaces of the tool and a cutting element fastening plane.

Conventionally, these products represent plates of various geometric forms and are made homogeneous or laminated depending on their purpose. They are mainly worked up by an abrasive tool (AT). Use of various abrasive wheels enables obtaining flat elements of surface (during cutting or profile ones during wheel periphery copying (Fig. 4, a).

An alternative consists in application of laser working methods, in particular, laser cutting (LC), laser cutting with a water cooling (LCC) or water jet guided laser (WJGL), and also a method using loose abrasive accelerated by a supersonic liquid flow - hydro-abrasive cutting (HAC). In this case the obtained surfaces can be of an arbitrary form determined by operational movement of the tool in relation to the worked surface (Fig. 4, c).

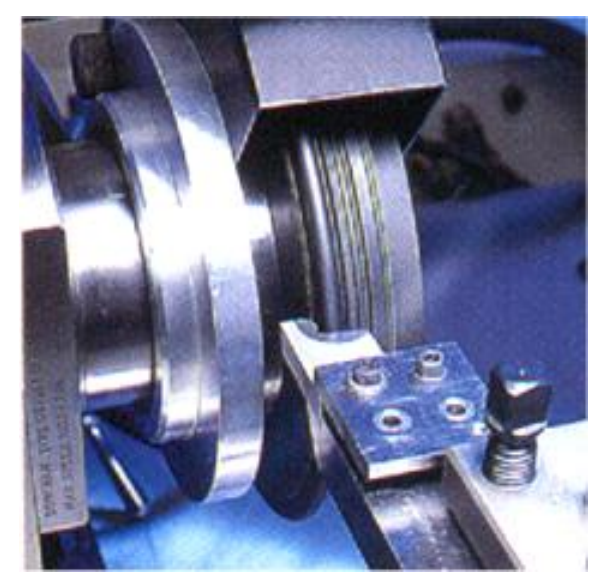

a

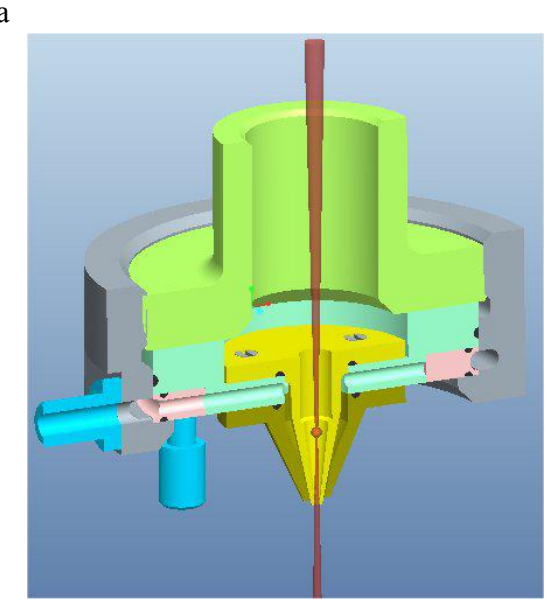

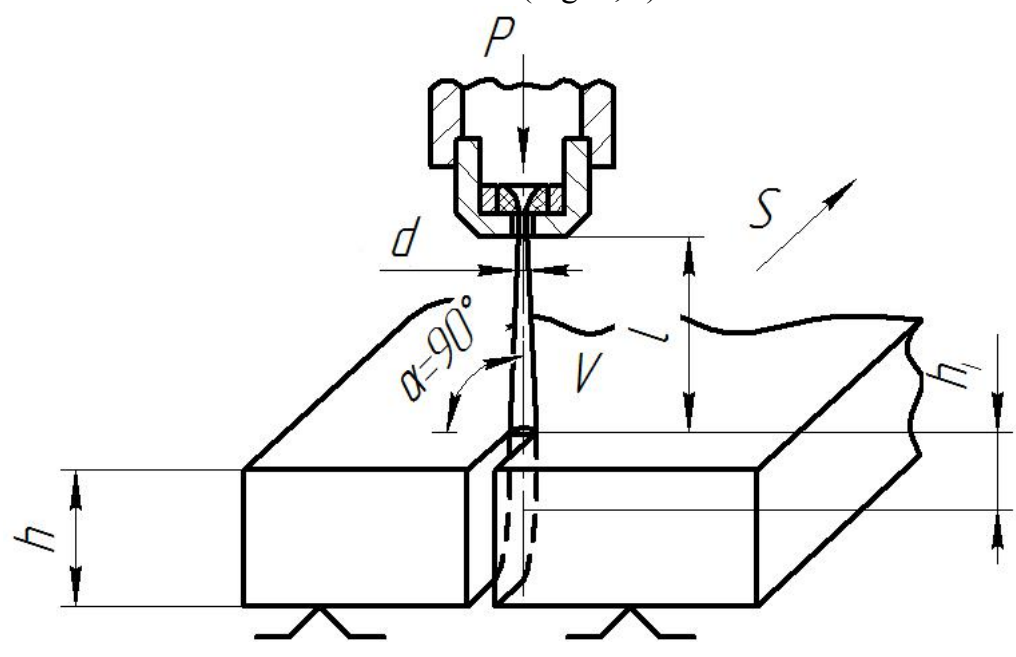

b

Figure 4; Processing tool working surface shaped abrasive wheel (a), model a jet device (b), a laser head for cutting the model

(c).

Features of application of these processes realized ordinary tools are discussed $\mathrm{in}^{[1,10]}$. But according preliminary research has revealed, separate application of these methods is not optimal. 
To apply the proposed functional approach, process models should be considered from a slightly different point of view.

HAC is known to generate a stressed condition at the obstacle - the worked surface; this state is described by components

$$
\sigma_{r}=2 G\left(\frac{\partial U}{\partial r}+\frac{\mu \varepsilon}{1-2 \mu}\right) ; \sigma_{t}=2 G\left(\frac{U}{r}+\frac{\mu \varepsilon}{1-2 \mu}\right) ; \sigma_{z}=2 G\left(\frac{\partial H}{\partial z}+\frac{\mu \varepsilon}{1-2 \mu}\right) ; \tau=2 G\left(\frac{\partial H}{\partial z}+\frac{\mu \varepsilon}{1-2 \mu}\right)
$$

then the deformation is determined

$$
\varepsilon=\varepsilon_{r}+\varepsilon_{t}+\varepsilon_{z}=\frac{\partial U}{\partial r}+\frac{U}{r} \frac{\partial H}{\partial z} ; \quad \varepsilon=\frac{1-2 v}{2(1-v) G}\left(\sigma_{r}+\sigma_{t}+\sigma_{z}\right)=\frac{1-2 v}{E}\left(\sigma_{r}+\sigma_{t}+\sigma_{z}\right)
$$

subject to

$$
\left\{\begin{array}{l}
(1-2 v)\left[\Delta U-\frac{U}{r^{2}}\right]+\frac{\partial \varepsilon}{\partial r}=0 \\
(1-2 v) \Delta U+\frac{\partial \varepsilon}{\partial r}=0 .
\end{array},\right.
$$

where $\mathrm{U}(\mathrm{t}), \mathrm{H}(\mathrm{t})$ - components of movements at a particular point of the surface that are determined as

$$
\begin{gathered}
U(t)=-\frac{(1-2 v) p_{o}(t)\left[\frac{D_{k}}{2}\right]^{2}}{4 G} ; 0<\frac{D_{i}}{2}<\frac{D_{k}}{2} ; \\
H(t)=-\frac{(1-2 v) p_{o}(t) D_{k}}{2 G}
\end{gathered}
$$

G, $\mu$ - shift module and Poisson ratio of the worked material, respectively; $\varepsilon$-volume deformation;

$$
\Delta=\frac{d^{2}}{d r^{2}}+\frac{d}{r \partial r}+\frac{d^{2}}{\partial z^{2}} \text { - Laplace operator, } \mathrm{p}_{0} \text { - pressure at the obstacle } p_{i}=0,5 \rho v_{i}^{2}+\rho v_{i}^{2} d Q .
$$

Intensification of the stressed condition contributes to development of initial defects ${ }^{[1]}$ and creation of a grid of microcracks actively joining under the action of abrasive particles when material particles come off the surface. HAC is characterized by the property to efficiently continue working only till the moment when the loss of jet energy due to friction against the surface of the funnel that appeared is comparable with the energy at which the cutting process ceases.

In particular, $\mathrm{in}^{[2,12]}$ it is shown that during working of carbides (HA) the dimple depth $\mathrm{h}_{1}$ increases due to manifestation of mechanisms of micro-cutting and deformation destruction, i.e. the process is described by expression

$$
h_{l}=c \sqrt{\frac{m_{a} v^{2}}{8 \sigma u^{2}}}+\frac{2 m_{a}(1-c) v^{2}}{\pi u \varepsilon D_{j}}
$$

particles movement, $\quad v=\frac{2 p_{b} f_{b}}{f_{b} \sqrt{2 p_{b} / \rho}+m_{a}} ; \sigma$-material flow stress; $\mathrm{u}-$ feed rate; $\varepsilon$ - material specific energy; $\mathrm{D}_{\mathrm{j}}$ - flow diameter corresponding to the diameter of the nozzle section.

On the other hand, according to the ${ }^{[12]}$ due to flow energy losses, the real depth of the obtained dimple will be less and can be taken into account by relation

$$
h_{l}=c \sqrt{\frac{m_{a} v^{2}}{8 \sigma u}}+\frac{\left(1-N_{1}\right)^{2} d_{j}}{\frac{N_{2} N_{3}}{1-c}+C_{f}\left(1-N_{1}\right)},
$$




$$
N_{1}=\frac{v_{c}}{v} ; \quad N_{2}=\frac{\pi}{2} \frac{\varepsilon d_{j}^{2}}{m_{a} v} ; \quad N_{3}=\frac{u}{v} ; \quad v_{c}{ }_{\text {- critical velocity of abrasive particles movement. }}
$$

A feature of cutting hard-composite workpieces used in tools both separately and in the form of bases for the required layers of other materials consists in the fact that particles flowing on the surface cause local highly intensive loads resulting in some elastoplastic compressive macrodeformations in local volumes of the surface layer. These loads are mainly received by the carbide structure (for alloys containing cobalt $\leq 10 \%$ ). Further pickup of the abrasive particle by liquid flow results in removal of compression load, partial elastic restoration of the deformed volume of the surface layer, i.e. in occurrence of tensions in this local volume, which causes redistribution of tensions among the components of HA structure. In this case, at first carbide grain boundaries break, which results in appearance of microcracks in HA carbide grains themselves and plastic deformation along the dislocation mechanism of cobalt bundle ${ }^{[10]}$. After that the boundaries between the carbide grains and the bundle and the bundle itself break.

Hence, movement of the destruction area slows down when the cutting depth increases and distortion of the jet as a "non-rigid" tool increases.

More possibilities are provided by combined working of material by Water Jet Guided Laser (WJGL). Such a conclusion can be made on the basis of ${ }^{[13-15]}$. In this case working variants correspond to schemes in Fig. 6 , in this case both LCC, Fig. 5, b, c, d, e, and WJGL, Fig. 5, a, can be realized.

The action of a water jet or a laser beam can be both simultaneous and successive. In this case different variants of laser blasting and possibilities of variation of the form of jet nozle flow section, as shown in ${ }^{[15]}$, provide good prospects in combination of methods of actions on the worked piece and, consequently, in meeting principle (10).

Application of thermo-hydro-dynamic jets typical of WJGL or LCC causes heating of the workpiece whose temperature field can be described by equation [14]

$$
\begin{aligned}
& e^{\frac{(x-v(t-z))^{2}}{4 \alpha \tau+A^{2}} \frac{y^{2}}{4 \alpha \tau+B^{2}}} \\
& T(x, y, z, t)=\frac{P}{\pi \frac{1}{2} \rho c} \int_{0}^{l} \times\left[e^{-\frac{z^{2}}{4 \alpha \tau}}-h^{*}(\pi \alpha \tau)^{1 / 2} \operatorname{erfc}\left(\frac{z}{2(\alpha \tau)^{1 / 2}}+h^{*}(\alpha \tau)^{1 / 2}\right) \times e^{h^{*} z+h^{* 2} \alpha \tau}\right] d t \\
& \text { where } \mathrm{t} \text { - time from the moment of beginning of thermal impulse action, } \rho, \mathrm{c}, \lambda, \quad \alpha=\frac{\lambda}{c p}, \mathrm{~h}^{*} \text { - density, specific heat }
\end{aligned}
$$

capacity, heat conductivity coefficient and temperature conductivity of the workpiece material, coefficient of heat transfer from the surface of the workpiece, respectively; A and B - bigger and smaller half-axes of beam elliptic section; $\mathrm{P}=\pi \mathrm{qAB}-$ power of the lasing emitter, integral equation of heat energy balance in an arbitrary area $\omega \subset \Omega$ according

$$
\text { to }^{[13]} \text { will take the form } \int_{w} \frac{\partial e}{\partial t} d v=\int_{w} g d v-\oint_{\partial w}\left(\overrightarrow{q_{T}}+c_{g} \rho_{g} T \overrightarrow{v_{f}}, \vec{n}\right) d s .
$$

Taking into account the boundary conditions in the cutting zone

$$
\begin{aligned}
& c \rho \frac{d T}{d t}-\lambda \Delta T=\frac{\left(T-R_{0}\right) k P}{\pi A B} \exp \times \\
& \times\left[-2\left(\frac{(x-v t)^{2}}{a^{2}}+\left(\frac{y}{b}\right)^{2}\right)\right] \times \exp (-k z)
\end{aligned}
$$

$$
\left.\lambda \frac{d T}{d z}\right|_{z=0}=\alpha(T)\left(T-T_{p}\right)
$$

temperature distribution across the sample section is obtained according Fig. 6. 


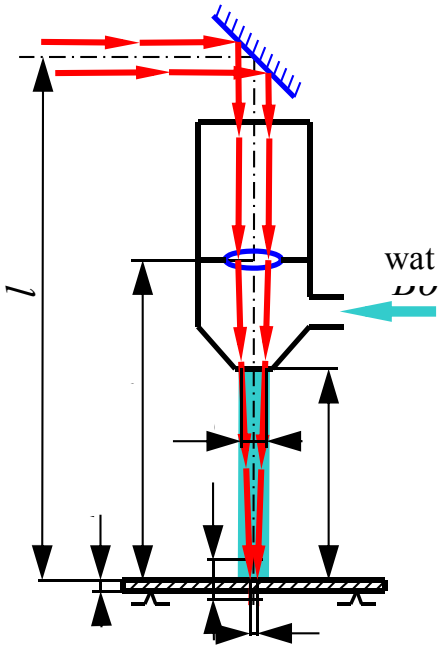

a

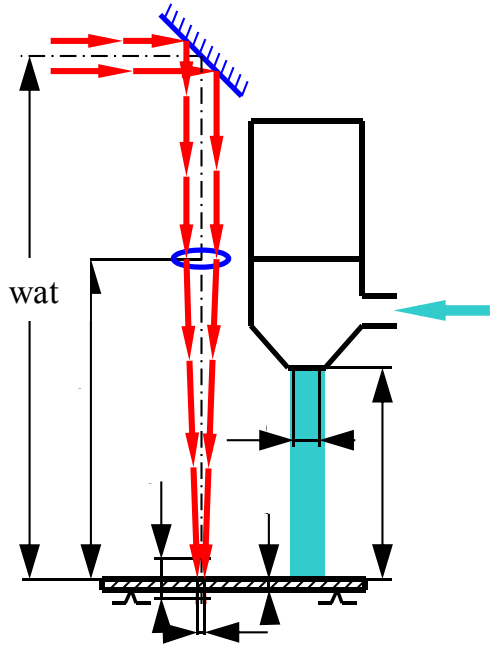

b

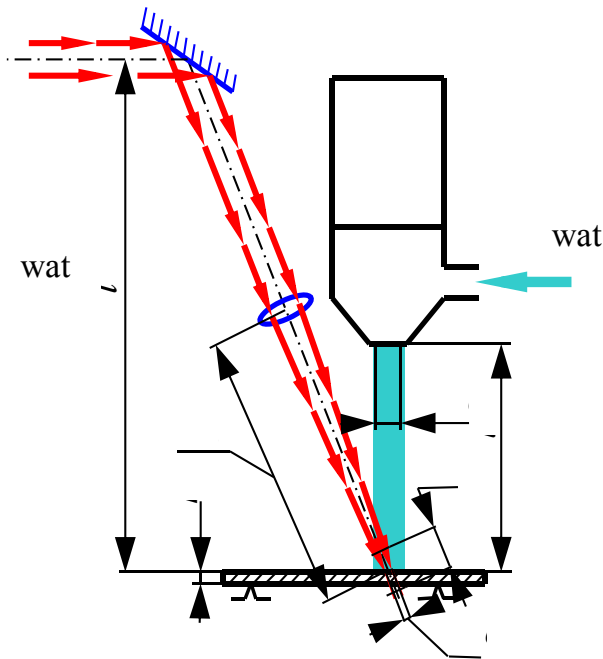

C

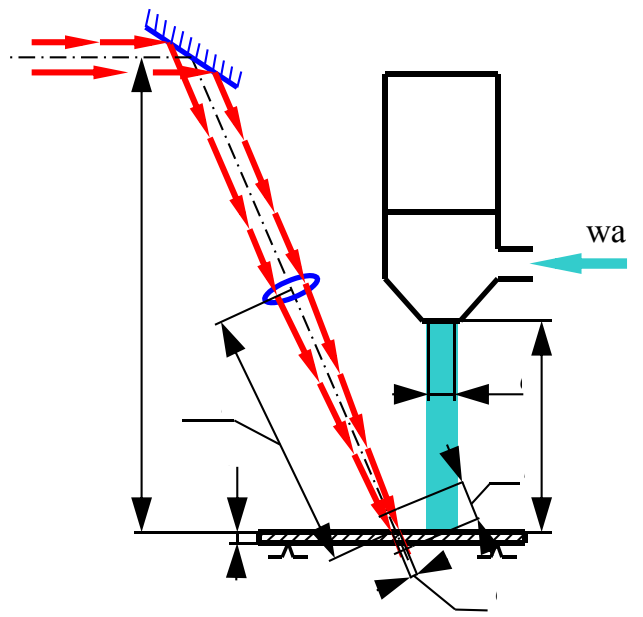

d

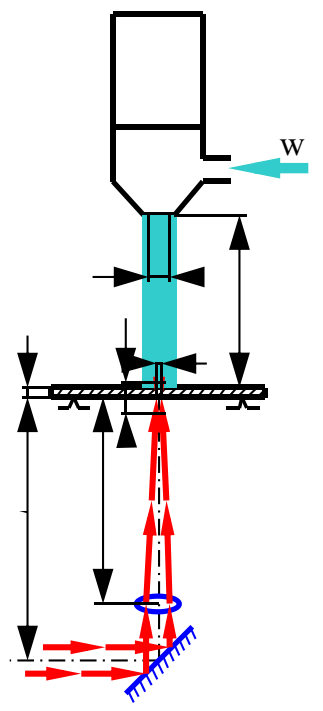

e

Figure 5; Variants of combination of a water jet and a laser beam for performance of LCC or WJGL.

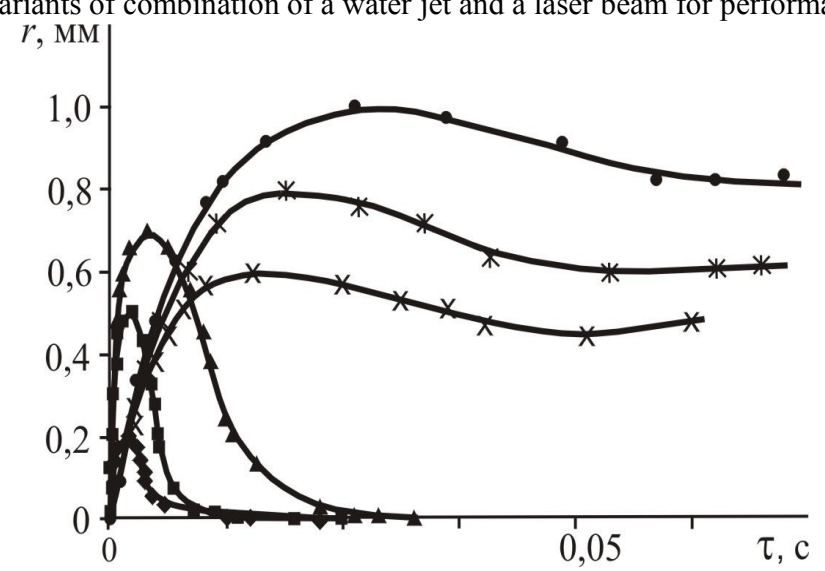

Figure 6; Changes in border-radius zone temperature field $\left(\mathrm{T}=850^{\circ} \mathrm{C}\right)$ as a function of time for different processing methods $\operatorname{LC}(\times, Ж, \bullet), \operatorname{LCC}(\boldsymbol{\Delta}), \operatorname{WJGL}(\diamond, \boldsymbol{\bullet})$.

Its analysis reveals the following (Fig. 6): temperature distribution across the surface is determined by conditions of coolant outflow and may considerably vary with the change of the flow shape; when the thickness of the sample 
increases, considerable reduction of the jet's ability to perform the work of destruction can be observed, as at the same amount of rejected heat the amount of delivered heat constantly decreases.

Consequently, by changing the flow rate, the laser pulse repetition rate (the amount of heat input), we change the form of the thermal action and the erosion zone. With the prevalence of heat in the local zone, the material is cut, with the prevalence of the heat sink on the larger surface - surface changes in the material, for example, recrystallization.

Process parameters such as pulse width and frequency of laser radiation, flow rate, nozzle shape, laser focus can be the elements determining the dependencies (8), Fig.2.

\section{Used equipment, workpieces and succession of experimental research}

Cut workpieces of HA T5K10, PSHM on the basis of CBN "borsinit" represented plates of the size $12.7 \times 12.7$ $\mathrm{mm}$, of the thickness up to $3.5 \mathrm{~mm}$, DC workpieces were two-layer composites of the size $12.7 \times 12.7 \mathrm{~mm}$ with an upper PCD-layer of the thickness up to $1.0 \mathrm{~mm}$ and a hard-alloy base of the thickness up to $3.0 \mathrm{~mm}$.

The cuts were performed by methods of hydro-abrasive (HAC), laser (LC) cutting, laser cutting with liquid cooling (LCC) and water jet guiding laser (WJGL).

Experiments were carried out with the use of laser blasting complex LSK-400-5, equipped with a hydro-abrasive head with water mozzle $\mathrm{d}_{\mathrm{c}}=0.22 \mathrm{~mm}$ and a metering tube $\mathrm{D}_{\mathrm{k}}=1.05 \mathrm{~mm}$.

HAC was performed with abrasive consumption - up to $0.5 \mathrm{~kg} / \mathrm{min}$ and under liquid pressure of $250 \mathrm{MPa}$. Garnet sand of granularity of 300 meshes was used as abrasive during cutting.

During multi-cut laser blasting the cuts were performed with feed up to $50 \mathrm{~mm} / \mathrm{min}$. Impulse Nd: YAG-laser with impulse frequency of 75-150 HZ, power $400 \mathrm{~W}$ was used. For realization of the hybrid process the unit was equipped with a special laser-blasting head enabling working with the use of a ring laser nozzle and a mixing chamber to provide hydro-abrasive cutting without disturbance of the position of basic axes of the tools. The beam was focused according to a method providing centering and ingress of all its modes on the focusing lenses of the tube. Optics elements were blown with purified compressed air through a nozzle of $\varnothing 2.8 \mathrm{~mm}$ under excess pressure of 0,05 MPa. During LB the liquid was fed directly into the center of laser focus under the pressure of 25-50 MPa.

\section{Discussion of the obtained results}

Paper ${ }^{[3]}$ contains comparative results of the research of productivity of different working methods. In the present paper experiments with workpieces made of HA and PSHM are repeated, but attention is focused on the indices of the quality of the worked surfaces - roughness and accuracy of relative position and also deviations of their values from theoretically possible ones.

Thus, the possibilities of HAC process from the point of view of the functional approach can be presented by elements of table 2. In this case the ability of the jet to destroy the obstacle with creation of vertical edges can be regarded as a useful function only for a restricted number of materials.

Then

$\mathrm{W}_{1 \mathrm{i}}\left(\mathrm{t}_{\mathrm{k}}\right)=\mathrm{W}_{1}{ }^{\mathrm{Fp}}\left(\mathrm{t}_{\mathrm{k}}\right) \cap \mathrm{W}_{1}{ }^{\mathrm{Fv} 1}\left(\mathrm{t}_{\mathrm{k}}\right)$

under the condition that $\mathrm{F}_{\mathrm{v} 2}$ and $\mathrm{F}_{\mathrm{n} 1}$ can be neglected and useful and harmful properties (functions) are manifested simultaneously. Corresponding transformations in the form of the process result, e.g. depth $\mathrm{h}$ (the surface element linear value) for HA may represent regression equations in the form:

$$
\begin{aligned}
& \left.h\right|_{W^{F p}}=b_{0}+b_{1} s_{k}+b_{2} M_{a} ; \\
& \left.\delta\right|_{W^{F v}}=b_{0}+b_{1} s_{k}+b_{2} h_{m},
\end{aligned}
$$

where $\mathrm{M}_{\mathrm{a}}$ - abrasive grains mass flow, $\mathrm{h}_{\mathrm{m}}$ - thickness of the worked material, for other materials

$$
\left.h\right|_{W^{F_{p}}}=0
$$




$$
\left.\delta\right|_{W^{F v}}=0
$$

It is obvious from the given relations that these two dependences are interconnected and increase of cutting depth $h$ at a higher rate of contour feed $\mathrm{sk}$ results in increase of waviness $\delta$.

We showed that much higher rigidity of polycrystal super-hard materials, including cubic boron nitride (PSHM, CBN) and diamond-bearing elements (DBE) causes the fact that a moving flow of abrasive grains slightly influences the worked material and the workpiece is not cut at a speed admissible by manufacturing conditions (Fig. 7, a ).

\begin{tabular}{|c|c|c|c|c|}
\hline \multirow[b]{3}{*}{ Worked material } & \multicolumn{4}{|l|}{ Functions F' } \\
\hline & \multirow{2}{*}{$\begin{array}{l}\text { Useful } F_{p i} \\
\text { Obtaining of } \\
\text { orthogonal edge of the } \\
\text { product } \\
\text { h, mm }\end{array}$} & \multicolumn{2}{|l|}{ Harmful F $F_{v k}$} & \multirow{2}{*}{$\begin{array}{l}\text { Neutral } \mathbf{F}_{\mathbf{n j}} \\
\text { Workpiece heat, } \mathbf{T} \\
{ }^{\circ} \mathrm{C}\end{array}$} \\
\hline & & $\begin{array}{l}\text { Waviness } \\
\delta, \mu \mathrm{m}\end{array}$ & Surface cleavage & \\
\hline HA & $\begin{array}{l}\mathrm{F}_{\mathrm{p} 1}-\text { depends on cutting } \\
\text { modes }\end{array}$ & $\begin{array}{l}\mathrm{F}_{\mathrm{vk}}-\text { depends on } \\
\text { cutting modes }\end{array}$ & Minimum & $\begin{array}{l}\text { Up to } 50- \\
60^{\circ} \mathrm{C}\end{array}$ \\
\hline PSHM & Weak & High & Complete & $\begin{array}{l}\text { Up to } 50- \\
60^{\circ} \mathrm{C}\end{array}$ \\
\hline PCD & Absent & Absent & Insignificant & Up to $50-75^{\circ} \mathrm{C}$ \\
\hline
\end{tabular}

Table 2. Provision of the product function by creation of element $E_{\mathrm{i}}$ by a technological action $\mathrm{W}_{\mathrm{ij}}\left(\mathrm{t}_{\mathrm{k}}\right)$ at $\mathrm{HAC}$

Obtaining the initial groove and creation of a cut or a channel result in distortion of the jet and its drift from the theoretic axis to the side opposite to the feed movement. It is facilitated by selectivity of destruction caused by "non-rigidity of the jet, due to which creation of specific destruction areas takes place (Fig. 7, b); their location and dimension determine the form of hydro-cutting front and deviation of the jet by angle $\alpha$, whose value is determined by relation of speed $\mathrm{v}_{\mathrm{z}}$ of jet penetration into the worked material and feed rate $\mathrm{s}$. This phenomenon results in appearance of surface defects in the form of waviness and also in cut edge deviation from orthogonality.

The jet ability to selectively go about obstacles results in the fact that heterogeneity of the worked material, specific features of the power scheme may provoke availability of both bumpy elements of the surface and surface cleavages (Fig. 7, c).

We also create a table of provision of the product with the function via formation of its separate element or a totality of elements. This table is analogous to the one considered above (e.g. for WJGL table 3), but it reflects the peculiar feature of each of the variants in Fig. 6. It should be noted that the given tables just illustrate the approach and draw attention to the most important functions while a totality of such functions may be much bigger.

On the basis of table 3. technological action for obtaining of a particular element can be presented as

$$
\mathrm{W}_{2 \mathrm{i}}\left(\mathrm{t}_{\mathrm{k}}\right)=\mathrm{W}_{1}{ }^{\mathrm{Fp} 1}\left(\mathrm{t}_{\mathrm{k}}\right) \cap \mathrm{W}_{1}{ }^{\mathrm{Fv} 1}\left(\mathrm{t}_{\mathrm{k}}\right) \cap \mathrm{W}_{1} \mathrm{Fv}^{\mathrm{Fv}}\left(\mathrm{t}_{\mathrm{k}}\right) \cap \mathrm{W}_{1}{ }^{\mathrm{n} 1}\left(\mathrm{t}_{\mathrm{k}}\right) .(14)
$$

Corresponding transformations for LB for different materials are to include four equations now (according to the number of components): 


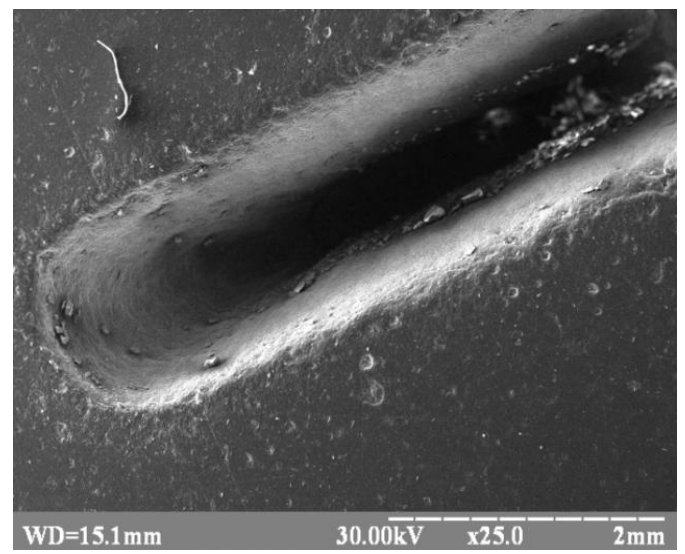

a

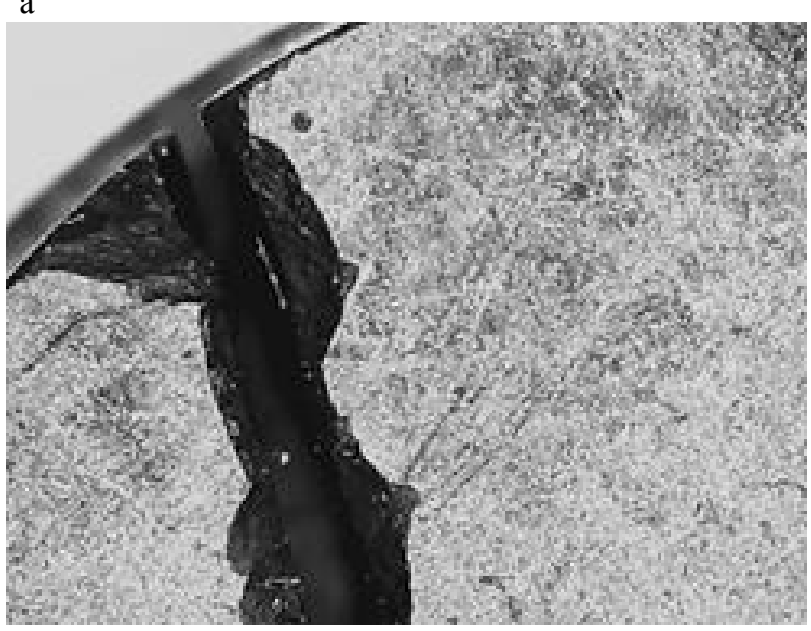

C

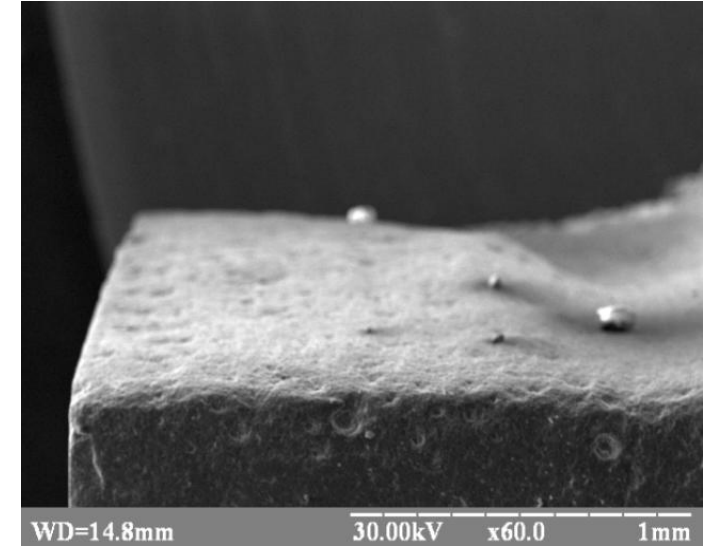

b

Figure 7; Surface defects as manifestation of harmful functions of technological actions: $a$ - incomplete cutting; $b$ - surface

$$
\begin{gathered}
\text { waviness; c - surface cleavages. } \\
\left.h\right|_{W^{F p}}=b_{0}+b_{1} s_{k}+b_{2} T+b_{3} Q_{v}+\ldots ; \\
\left.\delta\right|_{W^{F v}}=b_{0}+b_{1} s_{k}+b_{2} T+b_{3} Q_{v}+b_{4} h_{l}+\ldots \\
\left.l\right|_{W^{F v}}=b_{0}+b_{1} s_{k}+b_{2} T+b_{3} Q_{v}+b_{4} h_{l}+\ldots \\
\left.P\right|_{W^{F v}}=b_{0}+b_{1} s_{k}+b_{2} T+b_{3} Q_{v}+b_{4} h_{l}+\ldots
\end{gathered}
$$

where $\mathrm{T}$ - impulse energy, $\mathrm{Q}_{\mathrm{v}}$ - liquid discharge out of the nozzle, $\mathrm{h}_{1}$ - depth of the groove in the worked piece. Analogous tables, including ones with extended features of functions F' are created for all the types of working.

The obtained dependences (12), (14) make it possible to determine the totality of variants for carrying out the process of working of a particular element of the surface, and the most optimal method can be searched on the basis of morphological analysis. 


\begin{tabular}{|c|c|c|c|c|}
\hline \multirow[b]{3}{*}{ Worked material } & \multicolumn{4}{|l|}{ Functions $\mathbf{F}^{\prime}$} \\
\hline & \multirow{2}{*}{$\begin{array}{l}\text { Useful } F_{p i} \\
\text { Obtaining of } \\
\text { orthogonal edge of } \\
\text { the product (depth } \\
\text { h, mm) }\end{array}$} & \multicolumn{2}{|l|}{ Harmful $F_{v k}$} & NeutralF $_{\mathbf{n j}}$ \\
\hline & & $\begin{array}{l}\text { Thermodestruction } \\
\delta, \mu \mathrm{m}\end{array}$ & $\begin{array}{l}\text { Cracking } \\
\mathrm{l}, \mathrm{mm}\end{array}$ & $\begin{array}{l}\text { Variation of } \\
\text { porosity } \\
P\end{array}$ \\
\hline HA & $\begin{array}{l}\text { Intensive, linearly } \\
\text { depending on } t \\
\text { (number of cuts } \mathrm{N} \text { ) }\end{array}$ & Minimum & Exists & Absent \\
\hline PSHM & $\begin{array}{l}\text { Intensive, decreasing } \\
\text { with increase of } \\
\text { groove depth } \mathrm{h}_{1}\end{array}$ & Minimum & Minimum & $\begin{array}{l}\text { Is observed in } \\
\text { destructed zone }\end{array}$ \\
\hline PCD & $\begin{array}{l}\text { Nonlinear } \\
\text { medium-intensive }\end{array}$ & Essential & Absent & $\begin{array}{l}\text { Is observed in } \\
\text { destructed zone }\end{array}$ \\
\hline
\end{tabular}

Table 3. Provision of the product function by creation of element $E_{i}$ by a technological action $W_{i j}\left(t_{k}\right)-L C C, W J G L$

To determine components in tables 2, 3 the values of separate parameters whose averaged values are given in table 4 are determined. Comparison of erosion rates determining the rates of deepening of the cutting dimples is given in table 5. In this case only particular results of the research are shown; they are sufficient for hybridization of the process according to principle (10).

\begin{tabular}{|c|c|c|c|c|c|}
\hline \multicolumn{2}{|c|}{ Type of working } & HAC & $\mathbf{L C}$ & $\mathrm{LCC}$ & WJGL \\
\hline \multirow{2}{*}{\multicolumn{2}{|c|}{ Modes of working }} & $\begin{array}{l}100 \mathrm{~mm} / \mathrm{min}, 350 \\
\mathrm{MPa}, \\
0.5 \mathrm{k \sigma} / \mathrm{min}\end{array}$ & $\begin{array}{l}30 \mathrm{~mm} / \mathrm{min}, 400 \mathrm{~W} \text {, } \\
100 \mathrm{~Hz}\end{array}$ & \multicolumn{2}{|c|}{$\begin{array}{l}30 \mathrm{~mm} / \mathrm{min}, 400 \mathrm{~W} \\
100 \mathrm{~Hz}, 0.5 \mathrm{MPa}\end{array}$} \\
\hline & & \multicolumn{2}{|l|}{ - } & $2.80 \mathrm{~mm}$ & $1.05 \mathrm{~mm}$ \\
\hline \multirow{3}{*}{ HA } & $\mathrm{R}_{\mathrm{a}, \mu \mathrm{m}}$ & 12.5 & 6.3 & 6.3 & 3.2 \\
\hline & $\mathrm{h}, \mathrm{mm} / \mathrm{cycle}$ & 6.4 & 5.9 & 3.5 & 3.0 \\
\hline & $\delta, \mathrm{mm} / 5.0 \mathrm{~mm}$ & $0.3-0.9$ & $0.02-0.15$ & $0.02-0.09$ & $0.02-0.04$ \\
\hline \multirow{3}{*}{ PSHM } & $\mathrm{R}_{\mathrm{a}}, \mu \mathrm{m}$ & - & $6.3-3.2$ & 3.2 & $2.5-3.2$ \\
\hline & $\mathrm{h}, \mathrm{mm} /$ cycle & $<0.01$ & $3.0-3.2$ & 2.4 & $1.5-1.75$ \\
\hline & $\delta, \mathrm{mm} / 5.0 \mathrm{~mm}$ & 0.80 & $0.05-0.10$ & \multicolumn{2}{|l|}{$0.02-0.05$} \\
\hline
\end{tabular}

Table 4. Accuracy and roughness of the surfaces of workpieces made from HA and PSHM at different jet working methods

The performed research revealed the following. Any initial deviation of the cut shape, especially during performance of discontinuous working processes, distorts the jet and further working results only in deterioration of the quality of the product, first of all, due to progressive deviation of the cut shape. It concerns all the types of working. So, Fig. 7 demonstrates a defect of DC cutting in the form of deviation from orthogonality of the edge at partially incomplete cutting of PCD layer. A feature of two-layer DC consists in the fact that workability by a certain method changes on the surface obtained at the section, depending on the structure of the material and physical and mechanical properties. A peculiarity of DC consists in the fact that PCD is not practically worked by HAC, while it can be worked by LCC and WJGL. The carbide base is worked by HAC with high efficiency.

Comparison of the diagrams of cutting rates of DC and PSHM demonstrates (Fig. 8,a,b) that productivity of the process is determined by obtaining scribe in the superhard layer. HAC cutting of hard-alloy base is practically performed in an identical way (Fig. 8,c). 

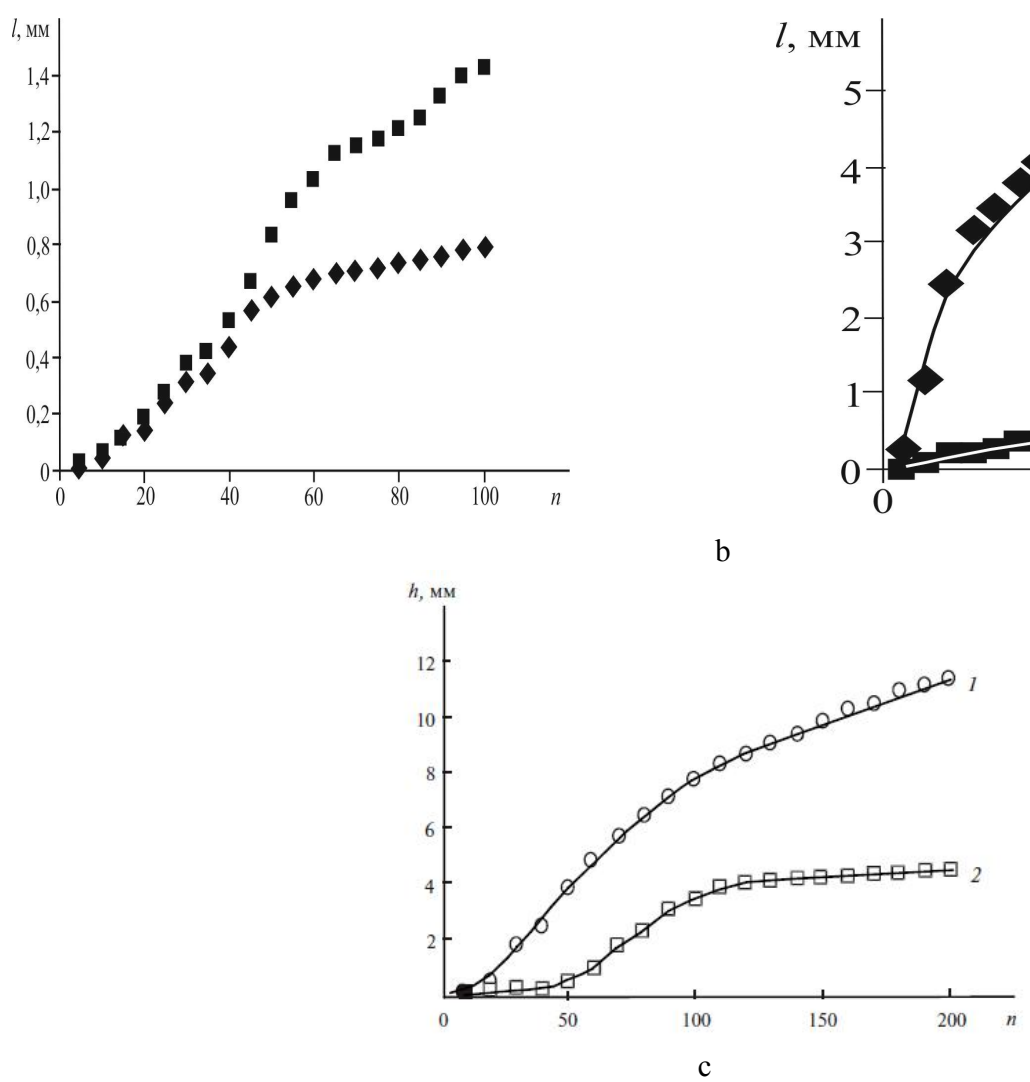

Figure 8; Depth change of scribe development ( a ) in workpieces from PCD ( $\bullet$ ) and PSHM ( $\mathbf{\square})$ depending on the number $\mathrm{n}$ of LCC cuts: linear feed rate - $35 \mathrm{~mm} / \mathrm{min}$, impulse passing frequency - $75 \mathrm{~Hz}$; a cutting depth in materials (HA - - PSTM - $\mathbf{\square}$ ) depending on the number $\mathrm{n}$ of LCC cuts (b); depth cutting in materials (HA - - ; PSTM - $\mathbf{\square})$ depending on the number $\mathrm{n}$ of HAC cuts (c): linear feed rate $500 \mathrm{~mm} / \mathrm{min}, \quad \mathrm{p}=290$ $\mathrm{MPa}$, abrasive consumption - $0,35 \mathrm{~kg} / \mathrm{min}$.

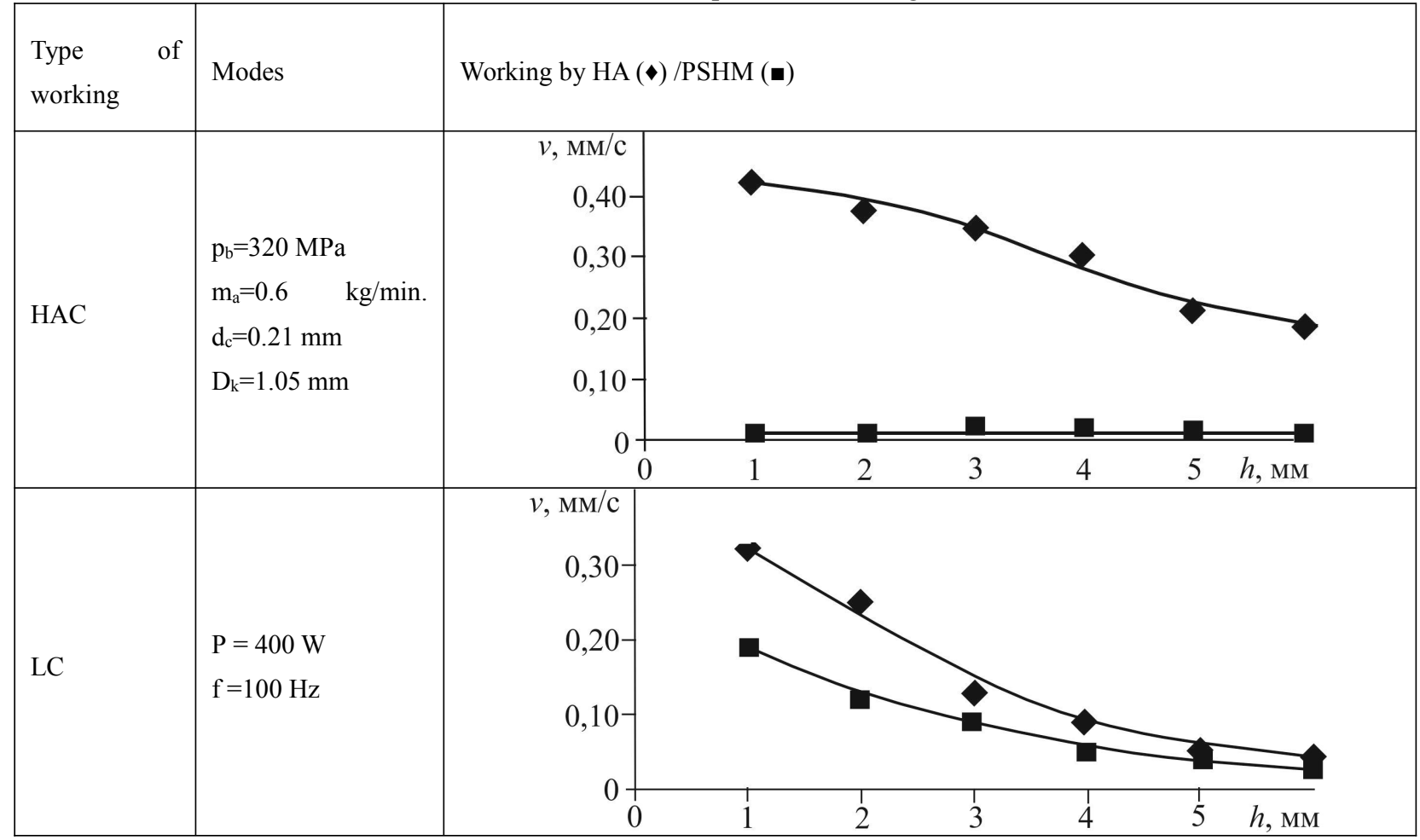




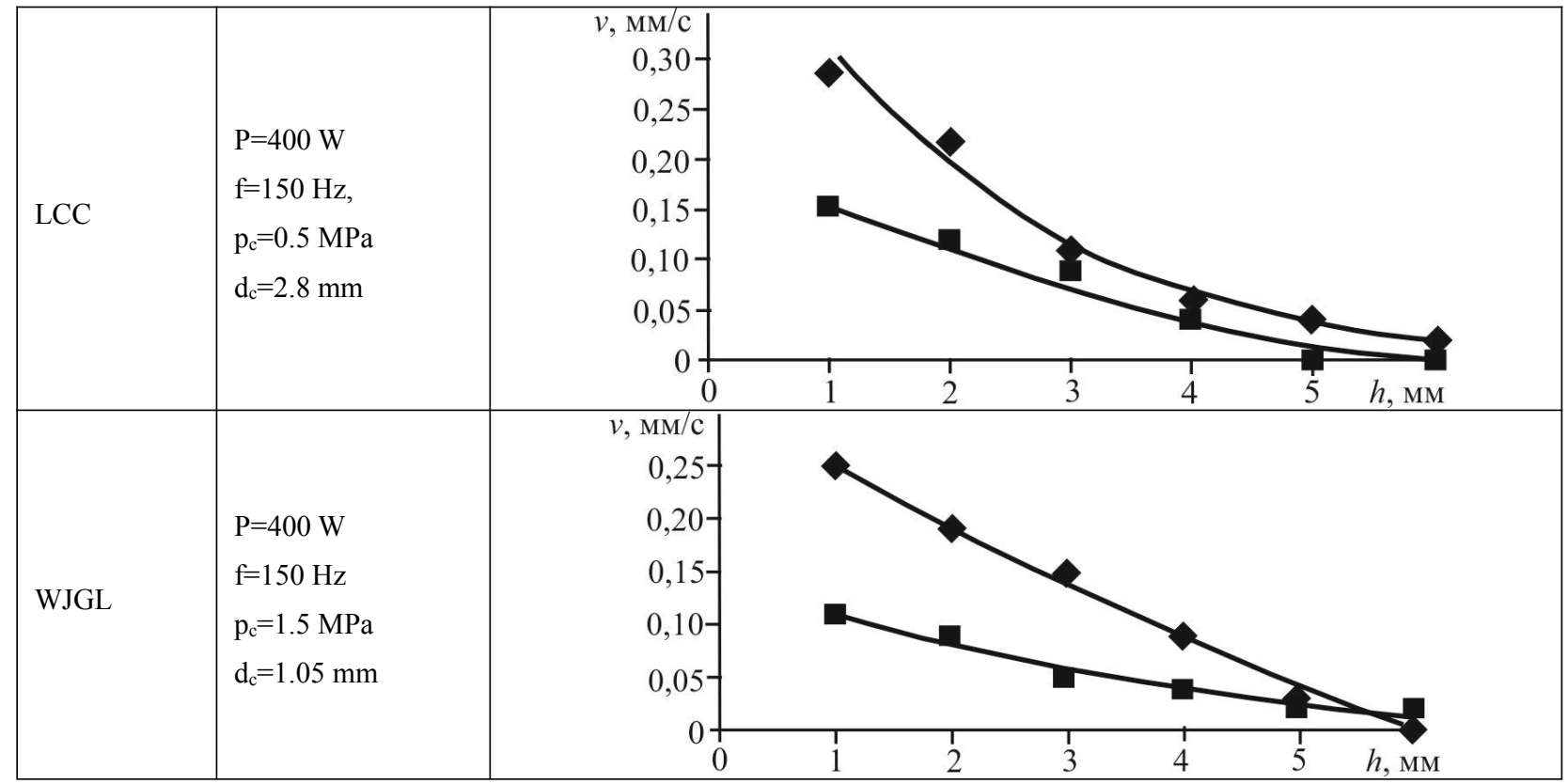

Table 5. Material erosion rate at HAC, LC, LCC, LB depending on the thickness of the plate

Hence, generation of the surface as an element of the product can be presented in the form of logical multiplication of transformations $\mathrm{W}_{1 \mathrm{i}}\left(\mathrm{t}_{\mathrm{k}}\right)$ and $\mathrm{W}_{2 \mathrm{i}}\left(\mathrm{t}_{\mathrm{k}}\right)$ and is described by expression

$$
\mathrm{W}_{\mathrm{p}}\left(\mathrm{t}_{\mathrm{k}}\right)=\mathrm{W}_{1}{ }^{\mathrm{Fp} 1}\left(\mathrm{t}_{\mathrm{k}}\right) \cap \mathrm{W}_{1}{ }^{\mathrm{Fv} 1}\left(\mathrm{t}_{\mathrm{k}}\right) \cap \mathrm{W}_{1}{ }^{\mathrm{Fv} 2}\left(\mathrm{t}_{\mathrm{k}}\right) \cap \mathrm{W}_{1}{ }^{\mathrm{n} 1}\left(\mathrm{t}_{\mathrm{k}}\right) \cdot \mathrm{W}_{1}{ }^{\mathrm{Fp} 1}\left(\mathrm{t}_{\mathrm{k}}\right) \cap \mathrm{W}_{1}{ }^{\mathrm{Fv} 1}\left(\mathrm{t}_{\mathrm{k}}\right)
$$

Thus, taking into account the condition of provision of initial high-quality formation of a destruction dimple in PCD-layer, a hybrid process is to represent a totality of processes of initial WJGL up to the moment of complete cutting of PCD-layer and creation of a dimple in WC with further cutting of the plate by HAC (Fig. 9).
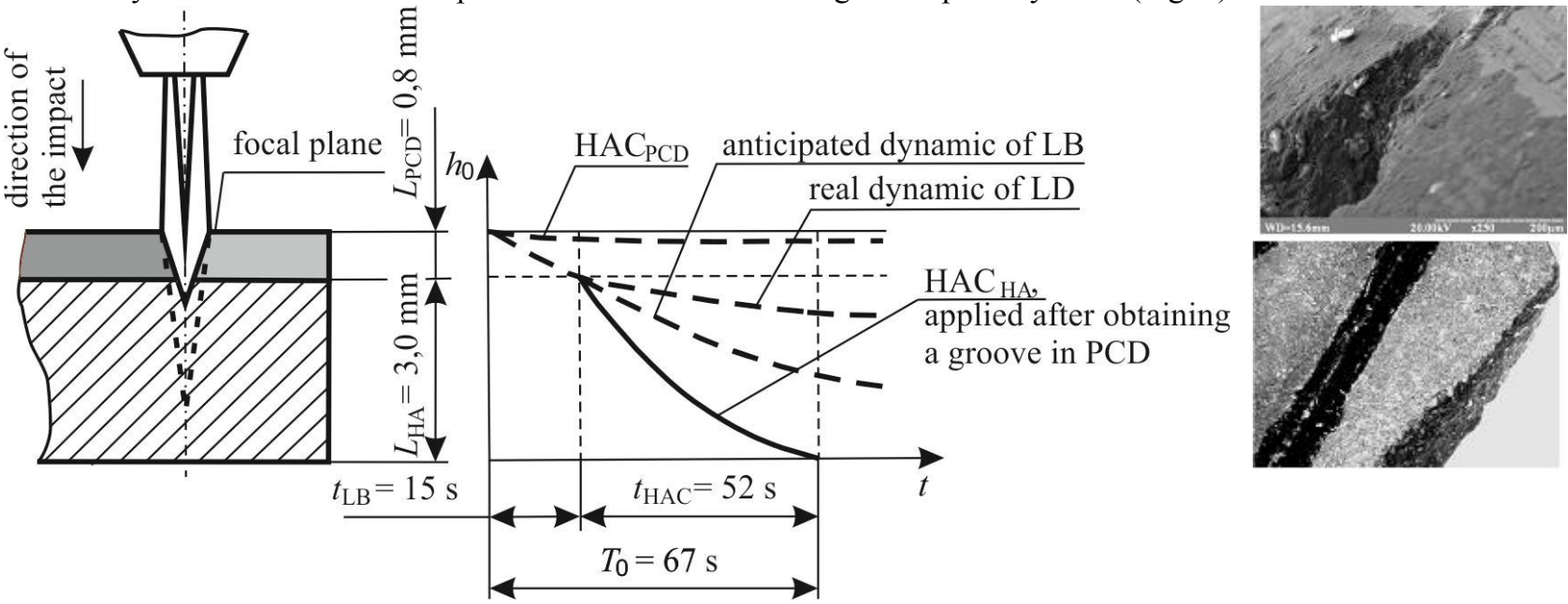

a) 

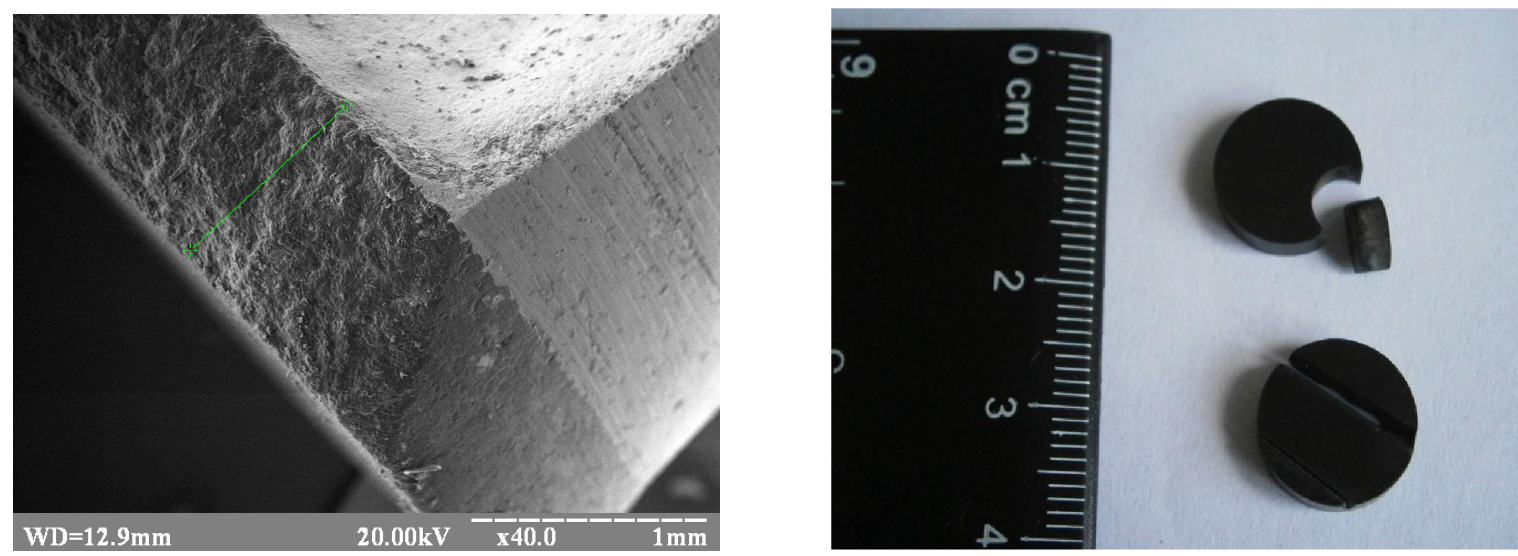

b)

Figure 9; Making a cut in PCD and PSHM workpieces (a) and a cut product (b).

Thanks to the proposed technology based on the use of a functionally oriented approach, the functions of the tool for cutting are divided between the tool itself and the product part. In the detail, this function is performed by a scribe made using the WJGL. As a matter of fact, this is an auxiliary tool (slot mask) for further processing of the HAC. The hydroabrasive flow actively and rapidly deepens the cut until the part is completely separated. As a result, the processing speed increases more than 3 times, and a high cut quality is achieved.

Further research is to be directed to determination of rational combinations of hybridization at multi-cut working, at which the number of cuts directly influences the quality of obtained surfaces, and also to the research of the condition of adhesion surfaces in multi-layer products.

\section{Conclusions}

Application of the functional approach makes it possible to reveal rational succession of TP steps, find optimal conditions and points of occurrence of harmful functions, eliminate them (or invert), and also determine the possibility of hybridization of the process. Such an approach can be used in working of composite workpieces from laminated superhard materials.

The performed research with the use of HAC, LC, LCC and WJGL has enabled studying of the intensity of destruction areas introduction into the worked piece and finding out the functional features of a particular process that are caused by the working conditions. It has been shown that the hypothesis of quasistationary rate of destruction is unacceptable for such materials, which is caused by the structure and high hardness of the material. It has also been determined that when deepening increases, the rate of jet introduction has a pronounced tendency towards reduction.

Particularity of cutting two-layer composites including a PCD layer based on HA has been analyzed and it has been shown that the use of functional approach principles makes it possible to propose a hybrid process and corresponding hybrid tool (combining WJGL and HAC), enabling efficient and productive cutting of such plates. Besides, conditions for essential improvement of working process efficiency have been demonstrated.

To improve the considered approach it is necessary to orientate further research to optimization of working conditions and search for ways of improvement of cut quality by selection of rational parameters of the process and design solutions for the hybrid tool.

\section{References}

1. Superhard materials. Obtaining and application: In 6 vol. / edited by N. V. Novikov. - K. : Nauk. dumka, 2003. vol. 1. $-320 \mathrm{p}$.

2. Salenko A. F., Shchetinin V. T., Fedotyev A. N. Improving accuracy of profile hydro-abrasive cutting of plates of hardmetals and superhard materials // J. of Superhard Mat. - 2014. - vol. 36, № 3. - P. 199-207.

3. Methods of cutting for workpieces of hardmetal and cBN-based polycrystalline superhard material / A. F. Salenko, V. T. Shchetinin, A. N. Fedotyev et. al. // J. of Superhard Mat. - 2015. - vol. 37, № 4. - P. 271-281.

4. A Decomposition Approach for Manufacturing System Design // David S. Cochran, Jorge F. Arinez, James W. Duda, 
Joachim Linck. - Department of Mechanical Engineering Massachusetts Institute of Technology Cambridge, MA, U.S.A. 02139.

5. R. S. Srinivasan, K. L. Wood and D. A. McAdams Functional Tolerancing: A Design for Manufacturing Methodology// Department of Mechanical Engineering, The University of Texas, Austin, USA. - Research in Engineering Design (1996) 2: 99-115 1996 Springer-Verlag London Limited.

6. Golibardov E. Method of functionally based analyze. - Kiyv, Technica, 1999. - 240 p.

7. M.S. Essersa, T.H.J. Vanekera A Function Based Approach for Designing Intelligent Flexible Automated Manufacturing Environments// 45th CIRP Conference on Manufacturing Systems 2012. doi: 10.1016/j.procir.2012.07.046.

8. French M. J. Design principles applied to structural functions of machine components // J. of Eng. Design. - 1992. -3 (3). - P. 229-241.

9. About some results of processing SiC-microarrays by Hydroabrasive Precision Jet / O. Salenko, G. Gabuzyan, Y. Myronov, V. Nikitin // J. of Mech. Eng. NTUU «Kyiv Polytechnic Institute». - 2013. - P.178-184.

10. Klimenko S. A., Mel'niichuk Yu. A., Vstovskii G. V. Interreation between the Structure Parameters, Mechanical Properties of Sprayed Materials and the Tool Life in Cutting Them // J. of Superhard Mat. - 2008. - vol. 30 , №. 2. - P. 115-121.

11. Synergy and fractals in Material Science / V. S. Ivanova, A. S. Balankin, I. Zh. Bunin, A. A. Oksogoiev. - M.: Nauka, 1994. - 384 p.

12. Hashish M., “Aspects of abrasive-Waterjet Performance Optimization”, Proceeding of 8-rd International Symposium on Jet Cutting Technology, Durham, England, 09.1996.

13. Simulation of Laser Cutting / W. Schulz, M. Niessen, U. Eppelt, K. Kowalick // The Theory of Laser: Mat. Proces. - John Dowden. Springer pb., 2009. - № 119. - P. 21-69.

14. Gindin P. D. A mathematical model of thermal cleaving of brittle anisotropic materials // Surface. - 2010. - № 1. P. 14-18.

15. Kholodnyi V., Salenko, O. (2016) The water jet guided laser method in punching honeycomb cores for aerospace sandwich panels, Eastern-European Journal of Enterprise Technologies, Vol. 1, № 5(79), pp. 19-30. DOI 10.15587/1729-4061.2016.59870 